\title{
Edición y política. Guerra fría en la cultura latinoamericana de los años ' 60
}

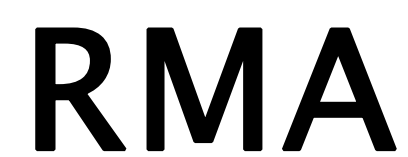

Antropología Social
Gustavo Sorá

CONICET / Museo de Antropología

Facultad de Filosofía y Humanidades, Universidad Nacional de Córdoba

gustavosora@gmail.com

\begin{abstract}
Resumen
La publicación de Los hijos de Sánchez por el Fondo de Cultura Económica, en diciembre de 1964, precipitó un cisma en la cultura mexicana. Para ciertos intelectuales ligados al poder, el libro de Oscar Lewis ofendía a la nación. Amparados por el gobierno autoritario de Gustavo Díaz Ordaz, provocaron la dimisión del director del Fondo de Cultura Económica, el argentino Arnaldo Orfila Reynal, acusado de «extranjero comunista». En reacción, quinientos intelectuales de todo el continente apoyaron a Orfila y lo estimularon para crear otra editorial: Siglo XXI. En el terreno de «la cultura», pocos acontecimientos produjeron la intensidad de posturas propias a la Guerra Fría. El objetivo singular de este trabajo es pensar por qué un combate de estas características estalló sobre el Fondo de Cultura Económica y sobre un editor singular. Su fin más amplio es contribuir a la reflexión sobre las condiciones bajo las cuales la edición se torna una práctica decisiva para la política.
\end{abstract}

Palabras clave: edición, política, intelectuales, circulación de ideas, internacionalización de la cultura.

Publishing and politics. Cold War in latin-american culture during the sixties

\section{Abstract}

The publication of Los hijos de Sánchez by the Fondo de Cultura Económica, in December of 1964, precipitated a rupture in the Mexican culture. For certain intellectuals related to the power, the book of Oscar Lewis offended the nation. Protected by the authoritarian government of Gustavo Diaz Ordaz, they caused the resignation of the director of the Fondo de Cultura Económica, the Argentinean Arnaldo Orfila Reynal, and defendant of «communist foreigner». In reaction, five hundred intellectuals of the entire continent supported to Orfila and they stimulated it to create another publishing house: Siglo $X X I$. In the land of «the culture», few events produced the intensity of own positions to the Cold War. The singular objective of this work is to think so that a combat of these characteristics exploded on the Fondo de Cultura Económica and a singular publisher. Its ampler aim is to contribute to the reflection on the conditions under which the edition becomes a decisive practice for politics.

Key words: publishing, politics, intellectuals, circulation of ideas, internationalization of culture.

«Los hijos de Kafka, mi querido doctor, se han vengado de los hijos de Sánchez»

(Carlos Fuentes al editor Orfila Reynal, en carta fechada en Roma el 16 de noviembre de 1965)

La publicación de Los hijos de Sánchez por el Fondo de Cultura Económica, en diciembre de 1964, precipitó un cisma en la cultura mexicana. Para un sector de intelectuales ligados al poder, la monografía del antropólogo norteamericano Oscar Lewis era una afrenta a la dignidad de México. Las vidas de los miembros de una «pobre» familia de suburbios, la fuerza de sus persistentes conductas tradicionales, mostraban fisuras en el desarrollo económico nacional. Sus testimonios, impregnados de un lenguaje "obsceno y soez», eran valorados por el antropólogo quien los interpretaba como signos de exclusión en una sociedad desigual y controlada por una política autoritaria. En febrero de 1965, Luís Cataño Morlet, prestigioso jurista y diplomático, encabezó el ataque contra el autor y el editor del Fondo, en una conferencia dictada en la Sociedad Mexicana de Geografía y Estadística a la que asistió el Presidente de la República Gustavo Díaz Ordaz. Fue el inicio de un escándalo que provocó la 
dimisión del editor Arnaldo Orfila Reynal, tras su estigmatización como «extranjero comunista». En reacción, quinientos intelectuales de todo el continente apoyaron a Orfila y lo estimularon para crear otra editorial: Siglo XXI. ${ }^{1}$ No interesa la cifra, sino la posibilidad de su enunciación como modo de imaginación de un verdadero ejército de agentes culturales movilizados por principios morales que convergían en la figura de ese editor. El alineamiento de esa internacional de intelectuales expresaba una historia de relaciones sociales tejidas, al menos desde mediados de los años 40, por la integración de luchas emprendidas en los distintos campos de poder nacionales en América Latina. Al tiempo de la dimisión de Orfila Reynal, la Revolución Cubana había sincronizdo y demarcado nítidamente los principios de acción y oposición entre todos los grupos enfrentados por el poder, en gran parte de occidente. Con Gustavo Díaz Ordaz, Presidente desde diciembre de 1964, el ala más conservadora del Partido Revolucionario Institucional (PRI) buscó clausurar el lugar de México como cuna de la ofensiva revolucionaria cubana y primer país en reconocer el gobierno de Dorticós. El affaire Orfila fue una de las primeras acciones de violencia estatal que anticiparon la "guerra sucia», cuyo ápice fue marcado por la masacre de estudiantes en la Plaza de Tlatelolco, poco antes del inicio de los juegos Olímpicos de $1968 .^{2}$

El Fondo de Cultura Económica fue fundado en noviembre de 1934 y en la segunda mitad del siglo XX devino una de las editoriales más importantes de Ibero-América. La Argentina representó un polo esencial para la difusión continental de esta empresa. Dos hechos apoyan esta afirmación: la fundación de la primera sucursal del exterior en Buenos Aires, en 1945, y la nominación de Arnaldo Orfila Reynal -líder de la Reforma Universitaria de 1918, socialista, emprendedor cultural- como director de la casa matriz en México D.F., en 1948. Su gestión ha sido retratada como «la edad de oro» del Fondo de Cultura Económica (FCE de aquí en más). El prestigio acumulado por Orfila Reynal acentuó en él un habitus carismático y patriarcal que lo llevó a vivir el FCE como «su casa», como un emprendimiento muy personal. Hacia finales de los años 50, el editor manifestó la radicalización de su pensamiento con la edición de libros comprometidos con el tercermundismo. Lentamente, traspasó los límites de lo aceptable para ciertos guardianes de la cultura mexicana y portavoces de una moral «occidental». Para los agentes que promovieron los cambios de mando en el FCE, el desplazamiento de Orfila era una condición para avanzar en un proceso de nacionalización y de control ideológico sobre un centro de irradiación internacional de las grandezas culturales del país, el cual, sentían, había girado peligrosamente a la izquierda, a causa de la acción del editor argentino. Estos sucesos, encuadrados en un contexto de época marcado por lo que algunos autores denominan la guerra fría cultural (Saunders 2001), repercutieron en toda América Latina. El objetivo singular de este trabajo es pensar por qué un combate de estas características estalló sobre el Fondo de Cultura Económica y sobre un editor singular, Arnaldo Orfila Reynal. Su fin más amplio es contribuir a la reflexión sobre las condiciones bajo las cuales la edición se torna una práctica decisiva para la política.

El control sobre la escritura es, desde la antigüedad, factor de intervención política. La evolución de las tecnologías para fijar el pensamiento y la diferenciación de funciones entre personas que escriben, que imprimen, que ponen en circulación y que leen textos, no han hecho más que amplificar el conjunto de reglas sociales que estructura el pensamiento y guía la transmisión de la cultura. El dominio de esas reglas tiene, como afirma Goody $(1977)^{3}$, significativas consecuencias para la configuración de las sociedades diferenciadas. El lugar de la escritura y de la edición en la emergencia de la esfera pública que subyace a los Estados nacionales, ya ha sido subrayado (Habermas 1984, Anderson 1993). La complejidad de ese vínculo fue intensamente abordada para comprender los orígenes culturales de la Revolución Francesa (Chartier 1995, Darnton 2008). Aplicado a la historia de América Latina en el siglo XX, este problema despeja un territorio poco explorado para comprender el clásico problema del lugar de la cultura en la construcción del poder.

El vínculo entre edición y política se desplaza entre dos posibilidades polares. Por un lado, un efecto que podríamos llamar diferido: el impacto de los impresos en la dinamización de la esfera pública. Por otro lado, un efecto directo: la edición de sistemas ideológicos concretos. ${ }^{4}$ ¿De qué manera los grupos que disputan poder se manifiestan, generan adhesión y luchan a través de la cultura impresa? La edición es una práctica estratégica para observar la acción de elites culturales que intervienen en la esfera pública a través de representaciones sobre el ciudadano, el público lector, la nación, la cultura, la educación, la política. El acto de publicar, de tornar público, de formar y atraer públicos, demarca la centralidad de la edición como medio generador de un pasaje fundamental en la constitución de la modernidad y los estados-nacionales: de la privacidad del escribir a la difusión, la recepción y la crítica de las ideas; de la interioridad del escribir a la interioridad del leer, mediadas por instancias públicas, por factores económicos (mercados de bienes simbólicos) y políticos (sistemas de enseñanza).

La figura del editor, sin embargo, rara vez se torna pública. En la escena de la cultura escrita comparte con el traductor, por ejemplo, una 
condición de relativa invisibilidad: ${ }^{5}$ esta es una de las paradojas más interesantes para el estudio de su lugar en la cultura. Lugar que puede ser revelado al considerar hechos extra-ordinarios como el que ilumino en este trabajo: la virtud heurística de un escándalo radica en el carácter de hecho crítico que, por la virulencia de las posturas que puede suscitar, deja al desnudo estructuras sociales y de pensamiento sublimadas durante el curso cotidiano de la vida cultural y política. ${ }^{6}$ El análisis del affaire Orfila permitirá pensar el lugar del editor como posible agente de la política y de la edición como un territorio significativo para las luchas por los poderes político y cultural. ¿Qué estructuras sociales y simbólicas atacó la intervención del Estado en el FCE? ¿Cuáles fueron los objetivos de esa intervención y qué efectos culturales y políticos produjo? ¿Cómo se explica una movilización de intelectuales tan espontánea y masiva en apoyo al editor extranjero y progresista? Este caso es estratégico ya que induce al tratamiento de relaciones internacionales generalmente obliteradas en los estudios sobre cultura y política, dominados por la inercia intelectual hacia el naciocentrismo (Elias 1989: 27): ¿Qué relaciones y apropiaciones del espacio intelectual internacional se observan en las disputas políticas que envolvieron al affaire Orfila? ¿Qué particularidades tuvo la guerra fría sobre la cultura mexicana y por qué tales sucesos impactaron en toda América Latina? ${ }^{7}$

\section{Estado y edición en México}

Desde inicios de la década de 1920 el Estado mexicano implementó políticas editoriales para combatir los fuertes índices de analfabetismo y para dar a luz grandezas del pensamiento nacional. Ya es famosa la colección de clásicos del pensamiento universal impulsada por José Vasconcelos en su período como Secretario de Educación del gobierno de Álvaro Obregón, a inicios de la década de $1920 .{ }^{8}$

Desde su creación en 1934, el FCE ha funcionado como un fideicomiso de múltiples entidades financieras del Estado mexicano: éstas realizan aportes económicos periódicos pero no se entrometen en la planificación del catálogo. Según los estatutos del FCE, la editorial no es una empresa del Estado, un patrimonio público, sino una entidad de servicio cultural. Esta forma jurídica garantiza autonomía, aún cuando el Ministerio de Hacienda siempre estuvo presente al designar a los presidentes de la Junta de Gobierno de la editorial y a otros miembros de la empresa. Este vector de presencia estatal estuvo controlado, durante los primeros 30 años del FCE, por el prestigio de sus dos primeros directores: Daniel Cosío Villegas (1934-1948) y Arnaldo Orfila Reynal (1948-1965). Sostén financiero directamente articulado con el ministro de economía de la nación y total independencia en la gestión cultural del catálogo: condiciones inigualables para realizar las apuestas de riesgo que los directores y asesores culturales del FCE imaginaban para la formación de nuevos cuadros universitarios, para ampliar la cultura del libro y para guiar el pensamiento de una cultura americana.

La editorial fue fundada bajo un clima de misión civilizadora, por un grupo de jóvenes académicos de la Escuela de Economía de la Universidad de México. Daniel Cosío Villegas se destacó en este grupo. Hijo de un funcionario federal del Correo, nació en la ciudad de México en 1898. Tras la derrota de Pancho Villa en 1916, comenzaron los primeros intentos por normalizar la vida institucional del país, orientados a la consolidación de un Estado, de un mercado capitalista y de políticas de educación y cultura. ${ }^{9}$ Durante este período, Cosío inició un veloz ascenso como el más destacado cuadro juvenil entre los círculos intelectuales que rodearon la afirmación de los primeros gobiernos revolucionarios - constitucionales: en 1921 fue Presidente de la Federación de Estudiantes, del I Congreso Internacional de Estudiantes y de la Internacional de Estudiantes que resultó de ese evento tan significativo para la vida de numerosos representantes de la cultura en América Latina, como el dominicano Pedro Henríquez Ureña, el peruano Haya de la Torre, el argentino Arnaldo Orfila Reynal. Durante la Presidencia de Álvaro Obregón (1920-1924), Cosío Villegas trabajó junto a José Vasconcelos en la Secretaría de Educación y no faltaron condiciones para imaginarse presidente de la república. ${ }^{10}$ Aún cuando ese gobierno marcó el inicio de la pacificación de México tras la Revolución de 1910, en los años 20 la vida institucional era periódicamente alterada por cambios de rumbo y luchas entre facciones. La inclusión de Cosío Villegas en círculos de sociabilidad intelectual de elites, como el Ateneo de la juventud, y la actividad universitaria, le permitieron sortear los avatares de la política. Para ello fue significativa su participación como el «benjamín» del círculo de notables Ilamado «de los siete sabios», conformado por Alberto Vásquez del Mercado, Manuel Gómez Morin, Vicente Lombardo Toledano, Teófilo Oléa y Leyva, Alfonso Caso, Antonio Castro Leal y Jesús Moreno Baca. También su colaboración con Antonio Caso en la cátedra de sociología de la carrera de derecho, que lo promovió a la situación de agente destacado en la afirmación de las ciencias sociales: desde 1922 dirigió la Revista de Ciencias Sociales de la Facultad de Jurisprudencia y en 1925 publicó una extensa Sociología Mexicana.

Al ser desplazado Vasconcelos al frente de la Secretaría de Educación, en 1924, el joven abogado Cosío Villegas «tuvo» que emigrar. Partió a los Estados Unidos y Europa para realizar estudios de 
postgrado en economía. Fue una acertada estrategia de reconversión: regresó en 1929 como especialista en reforma agraria y fue nombrado Secretario General de la Universidad Nacional. Ese mismo año impulsó la creación de la Escuela de Economía junto a Manuel G. Morin, Eduardo Villaseñor, Antonio Espinosa y Emigidio Martínez Adame. Al tiempo que la depresión económica mundial golpeaba fuertemente a México, la economía pasó a ser valorada como una herramienta indispensable para planificar nuevas alternativas para afirmar el Estado, el mercado y la cultura del país. Los objetivos de la fundación de la revista El Trimestre Económico y de la editorial FCE en 1934, fueron disponer un medio de comunicación académica de alto nivel y un stock bibliográfico para la formación de un nuevo tipo de agente cultural: los expertos.

A pesar de la rica historia de la imprenta hasta mediados del siglo XIX (Suárez de la Torre 2001 , Castañeda 2002), el desarrollo de la industria mexicana del libro se vio fuertemente condicionada por la turbulencia política y la exclusión de la mayoría de la población a la alfabetización y la lectura. Hacia 1912 sólo existían 3 editoriales y cuatro libreros-editores. En 1914 se fundaron dos sellos a partir de librerías que irían a asentarse como editoriales «modernas»: Porrúa Hermanos y Andrés Botas. En 1921, el 72\% de la población era analfabeta y en 1934 lo seguía siendo el 62\% (Meyer 2000: 152). Además de la colección de la Secretaría de Educación, durante el gobierno de Obregón la Secretaría de Relaciones Exteriores también inició un programa de publicaciones (Acevedo Escobedo 1962: 415 y ss.). A pesar de este empeño, la edición española y francesa dominó, hasta mediados de los años 30, las ofertas del mercado librero y las posibilidades de publicación de los escritores nacionales. Bajo este panorama, los directivos de la Escuela de Economía propusieron un programa de traducciones a Espasa \& Calpe de Madrid. Ante la negativa del renombrado filósofo Ortega y Gasset, principal consejero de esa editorial, buscaron apoyo en el gobierno. ${ }^{11}$ Hacia 1934, Cosío y Martínez Adame trabajaban en la Secretaría de Hacienda, la cual venía de implementar una ley de fideicomiso, dispositivo equivalente al trust sajón que habilitaba la aplicación de fondos públicos al servicio de fines no lucrativos. Fue así que convocaron a Gonzalo Robles, otro aliado del grupo que dirigía el Banco Hipotecario Nacional, quien coordinó la implementación de un fideicomiso para el FCE con el aporte de varias entidades financieras. La junta de gobierno que estipulaba este modo de organización estuvo compuesta por un grupo de jóvenes de una vanguardia intelectual comprometida en políticas de Estado: Gonzalo Robles, Manuel Gómez Morin, Eduardo Villaseñor, Emigidio Martínez Adame, Adolfo Prieto y Cosío Villegas. Morin y Prieto fueron sustituidos poco después por Enrique Sarro y Jesús Silva Herzog. La estabilidad de este grupo, sostenida por estrechos lazos de amistad, garantizó la construcción de un esprit de corps, disposición subyacente en el perfil editorial del FCE hasta la sustitución de Orfila Reynal.

El grupo y las líneas del catálogo, sin embargo, terminaron de delinearse hacia 1939, cuando la editorial se rodeó de los más destacados intelectuales y editores españoles que arribaron a México como republicanos exiliados (p.e. José Gáos, José Medina Echevarria, Enrique Díez Canedo, Francisco Giner de los Ríos, Eugenio Ímaz). La llegada de los transterrados marcaba el inicio de un proceso multi-causal de internacionalización de la cultura en gran parte de América Latina. En el plano editorial, la guerra civil y la segunda guerra mundial clausuraron España como principal mercado productor de libros en castellano. Ello abrió perspectivas para que algunos editores (muchos de ellos de origen español) asentados en Argentina y México se lanzaran a la provisión de los restantes mercados del libro del sub-continente. Editoriales argentinas como Losada, Sudamericana, Emecé, Santiago Rueda y Claridad, marcaron el terreno con la difusión de la literatura argentina, latinoamericana, internacional. El FCE aprovechó el espacio para la comercialización de colecciones dedicadas a múltiples disciplinas sociales y humanísticas. A partir de 1945, concretó proyectos editoriales para la imaginación de una cultura americana con el lanzamiento de las colecciones Tierra Firme y Biblioteca Americana. Estas fueron planificadas desde 1941, cuando Daniel Cosío Villegas inició un ciclo de viajes por América del Sur que generó un tejido de alianzas entre centenares de intelectuales convocados especialmente para escribir ensayos sobre las culturas y problemas específicos de América (latina). Esa experiencia informó el potencial de la fundación de una subsidiaria en Argentina, en 1945. Tal apuesta aceleró la consagración internacional de los proyectos del FCE (Sorá 2008a). ${ }^{12}$ En ese contexto reaparece la figura de Orfila Reynal.

\section{Un extranjero socialista}

Arnaldo Orfila Reynal asumió la dirección del FCE en 1948, una vez que Cosío Villegas dejó ese cargo para radicarse en los Estados Unidos con una beca Rockefeller y dedicarse a la escritura de una monumental historia de su país. Podríamos decir que para Cosío, la edición representó una mediación entre sus aspiraciones a la alta política y a la cumbre del mundo intelectual. Orfila, en cambio, fue un editor tout court. Tres variables explican su elección como extranjero al frente de una de las principales usinas culturales de México: el vínculo personal con Cosío Villegas y muchos de los intelectuales ligados al FCE; la experiencia 
de gestión de emprendimientos culturales, especialmente el éxito en la dirección de la sucursal argentina del FCE a partir de 1945; un perfil cosmopolita orientado por su «vocación» reformista, humanista, americanista.

Arnaldo Orfila Reynal nació en La Plata en 1897 y fue nieto del aragonés Mateo Orfila, un pionero en la formulación de la toxicología. Fue alumno de la primera cohorte del Colegio Nacional de la Universidad Nacional de La Plata. ${ }^{13}$ En esta universidad también obtuvo el grado de Doctor en química a inicios de los años 20. Su reconocimiento como líder político y promotor cultural comenzó a forjarse durante las huelgas estudiantiles que rodearon a la declaración de la reforma universitaria argentina de 1918. Por su participación en estos hechos, fue elegido delegado nacional para el ler Congreso Internacional de Estudiantes, realizado en ciudad de México, en 1921. Al terminar el Congreso, Orfila fue escogido, entre otros representantes, para viajar durante tres meses por varios países (Estados Unidos, Francia, Italia, España, Portugal y Brasil) con el fin de contactar asociaciones estudiantiles y sumarlas al organismo internacional creado por el Congreso. Desde entonces trabó amistad con Cosío Villegas, Pedro Henríquez Ureña, Alfonso Reyes, Carlos Pellicer, Jesús Silva Herzog, Miguel Gómez Morin y gran parte de los intelectuales americanistas que posteriormente gravitaron sobre el FCE.

A inicios de la década de 1920 se observa la disposición de Orfila Reynal para articular relaciones internacionales entre agentes y proyectos intelectuales y políticos: José Vasconcelos pidió que el joven Orfila fuera su anfitrión durante la visita oficial que realizó a la Argentina en 1922; Pedro Henríquez Ureña le solicitó, dos años después, algún empleo para radicarse en Argentina, ante el incierto panorama de la cultura y la política en México. ${ }^{14}$ La actividad cultural fue el terreno donde Orfila optimizó esa vocación. Por esos años, participó de Renovación, un grupo cultural de La Plata que rodeó a la figura del filósofo Alejandro Korn. ${ }^{15}$ En Valoraciones (1924 - 1928) revista cultural de vanguardia creada por Renovación, es posible rastrear el rol de Orfila como agente de articulación internacional. Él no firmó artículos, pero es evidente su activa participación en la solicitud de colaboraciones y en el tejido de una red entre intelectuales hispanoamericanos. ${ }^{16}$ Luego del primer golpe de Estado en Argentina, en 1930, Korn y la mayoría de los miembros de Renovación se afiliaron al Partido Socialista. Al morir el filósofo, en 1937, se creó la Universidad Popular Alejandro Korn en la sede platense de ese partido. Orfila Reynal dirigió esta institución hasta su nombramiento como director de la sucursal argentina del FCE, en 1945. Poco antes de la fundación de la UPAK, había viajado a España como corresponsal de $L a$
Vanguardia, diario del Partido, para cubrir el desenlace de la guerra civil. En Barcelona y Madrid conoció a algunos de los dirigentes e intelectuales republicanos que luego se exiliarían en México y Argentina.

Durante la gestión de Orfila como Director Gerente, el FCE creció como empresa y diversificó el catálogo. En los años 40, la editorial había alcanzado notoriedad continental como productora de traducciones imprescindibles para la renovación de las ciencias sociales y humanas, ${ }^{17}$ y como medio de expresión del ensayismo sobre los problemas de América. En los primeros años bajo la dirección de Orfila, el catálogo se abrió en dos marcadas direcciones: la promoción de obras de autores mexicanos y la búsqueda del lector masivo que emergía en gran parte del continente gracias a la ampliación de la alfabetización y de la matricula universitaria, y a la profesionalización de las ciencias sociales. Expresión de la primera apuesta fueron la colección Letras Mexicanas, por donde aparecieron los textos centrales de la vanguardia literaria de los años 50 , con Octavio Paz, Juan Rulfo y Carlos Fuentes al frente, ${ }^{18}$ y la colección Vida y Pensamiento de México. La segunda apuesta fue abierta con las colecciones Breviarios y Popular. Esos proyectos guiaron la definitiva consagración del FCE como empresa cultural estratégica para la divulgación internacional de las grandezas culturales de México y del continente. ${ }^{19}$ Por esos años la editorial construyó un gran edificio propio, abrió sucursales en Chile y España, y llegó a contar con una planta de alrededor de 100 empleados. No puede pasar por alto que la notoriedad alcanzada por Orfila como gestor del FCE le valió un contrato de tres meses durante 1957 para proyectar la editorial de la Universidad de Buenos Aires.

El siguiente testimonio de Martí Soler, quien fue uno de los más estrechos colaboradores de Orfila Reynal desde finales de los años 50,20 permite dimensionar algunos resortes de la planificación del catálogo del FCE, especificar las propiedades de la posición de Orfila Reynal y evaluar aquello que fue atacado en 1965, tras su dimisión: «Mi opinión personal acerca de Orfila es que no fue un gran editor, fue un gran administrador que supo rodearse de grandes editores». ${ }^{21}$ Para Martí Soler, los Breviarios pudieron haber sido planificados por Cosío Villegas al final de su gestión y Letras Mexicanas habría sido un plan del gerente de producción Joaquín Diez Canedo. Este comentario evita caer en las trampas de la ilusión biográfica al trabajar sobre la trayectoria de un editor: una editorial es antes que nada un espacio de relaciones sociales. Durante la gestión de Orfila, para Soler los grandes editores del FCE fueron Joaquín Diez Canedo, Ali Chumacero y Laurette Séjourné. ${ }^{22}$ Soler y otros retratan a Orfila Reynal como un gran administrador, alguien extremadamente riguroso que se 
posesionaba del lugar de trabajo, se vinculaba personalmente con los empleados y controlaba el ritmo de todas las fases de la labor diaria. Esa actitud también fue posible por sus lugares de residencia: Orfila nunca poseyó propiedad inmueble. En México, siempre vivió en departamentos situados en los predios de las empresas.

La impresión de Martí Soler invita a profundizar aún más en la complejidad de la vida editorial, tensionada entre los polos intelectual y económico que le dan sentido. «Rodearse» surge, en su discurso, como función secundaria de la labor editorial. Guiado por el criterio literario e intelectual restringido que domina (a) la representación de la función-editor, para él editor es quien orienta la elección de títulos y autores. A diferencia de Cosío Villegas, Orfila no fue «un autor»y eso mina su apreciación como «intelectual» y como «editor». Sin embargo, desde un punto de vista sociológico que pueda abarcar aquella tensión entre economía y cultura, la función de integración social que se expresa en el rodearse, en tejer vínculos y generar todo un sistema de relaciones sociales (una comunidad de autores, lectores, traductores que se objetiva en el catálogo, pero también una comunidad laboral poblada por empleados, proveedores, etc.), deviene una propiedad primaria de la posicióneditor. ${ }^{23}$ Esa activa función de mediación otorga a esta clase de editores el poder de devenir centro neurálgico para el encuentro y la sinergía entre proyectos y trayectorias distantes y orientadas con sentidos convergentes. Esto es lo que tornó a Orfila Reynal un hombre poderoso; esto es lo que fue atacado en 1965.

A pesar de los condicionamientos que suponían la consagración de la editorial como un símbolo de la nacionalidad y su asociación con un aparato de la burocracia estatal, Orfila imprimió su marca personal al FCE. Con el correr de los años, acentuó la identificación del catálogo con sus propios ideales culturales y políticos. Por un lado remarcó continuidad con el perfil del americanismo que compartía con Cosío, Silva Herzog y los demás intelectuales ligados al FCE. Por otro lado, sin embargo, abrió el catálogo a la expresión del pensamiento crítico que dominó la escena intelectual desde mediados de los años 50: por un lado la profesionalización de las ciencias sociales y por otro la avanzada política de izquierdas marcada por el tercermundismo y la revolución cubana. En los años 50 se observa una acentuada radicalización del pensamiento de Orfila Reynal con respecto al reformismo y la tradición social-demócrata del PS argentino. Según testimonios de personas próximas al editor, una razón central fue el papel jugado por Laurette Séjourné. Al poco tiempo de llegar a México, Orfila Reynal se separó de su primera esposa, María Elena Satostegui y se unió a Séjourné, arqueóloga francesa que había sido la mujer de Victor Sèrge, desde el arribo del legendario revolucionario soviético a México, en 1941, y hasta su muerte en 1947. Este vínculo sintetiza la adhesión Laurette a una izquierda revolucionaria anti-estalinista. Numerosos testimonios resaltan su marcada presencia en las elecciones culturales y políticas de Arnaldo en los años 50. La impronta de Séjourné se expresaba en una marcada predilección de Orfila para la edición de la vanguardia intelectual europea del período. ${ }^{24}$ Todos los años la pareja realizaba un viaje a la Argentina y otro a Francia. Aquí entablaron vínculos de amistad o de alianza estratégica con editores como François Masperó y escritores e intelectuales como Claude LéviStrauss y Jacques Lacan.

A mediados de la década, Orfila Reynal habría sido uno de los primeros en recibir a Ernesto Guevara Lynch al llegar a México. Su obsequio de El Capital en edición del FCE, es recordado como rito iniciático. ${ }^{25}$ Su participación en la ofensiva revolucionaria pudo haberse limitado a la acción como agente de enlace y formador de grupos de apoyo. Según Tatiana Coll, ${ }^{26}$ Orfila Reynal era «un hombre muy abierto, muy inquieto, que tenía miles de contactos con muchísima gente». Coll también recuerda que los diarios de época nombraban al editor como uno de los individuos que, a las pocas semanas del asalto revolucionario de enero de 1959, tomaron la Embajada de Cuba en México para exigir la renuncia del embajador batistiano y nombrar en su lugar a la exiliada Teté Casuso. Martí Soler, por su parte, recuerda que a inicios de los años 60, el FCE era un sitio de encuentro de la intelectualidad de izquierdas. Orfila no dudó en ofrecerle un puesto en el departamento de ventas al hijo de Miguel Ángel Asturias, Rodrigo, cuando tuvo que exiliarse como líder de la guerrilla guatemalteca. ${ }^{27}$ También fue amigo personal de Raúl Roa, Ministro de Relaciones Exteriores de Cuba entre 1959 y 1976, reconocido escritor antes de la revolución y uno de los principales cronistas de la misma. El propio Osvaldo Dorticós, Presidente de Cuba entre 1959 y 1976, visitó a Orfila en la editorial durante su primer viaje al exterior. ${ }^{28}$

Para Orfila Reynal el FCE era «su casa» en todos los sentidos del término. ${ }^{29}$ Se sentía «dueño» del FCE, es decir seguro de la autonomía formal y simbólica forjada por la editorial y por su gestión, a través de un sostenido reconocimiento internacional. Por ello actuaba sin aparente sensación de vigilancia, como agente que expresaba una visión de mundo fundada en una tradición humanista renovada a la luz de la esperanza cubana, revolución que prometía realizar una obsesión de su pensamiento: la autonomía e integración de las culturas de América (Latina). Orfila no escribió «libros», pero sí artículos para La Gaceta del Fondo de Cultura Económica ${ }^{30}$ y centenas de cartas personales en las que pueden rastrearse sus esquemas de pensamiento y acción. Uno de los primeros 


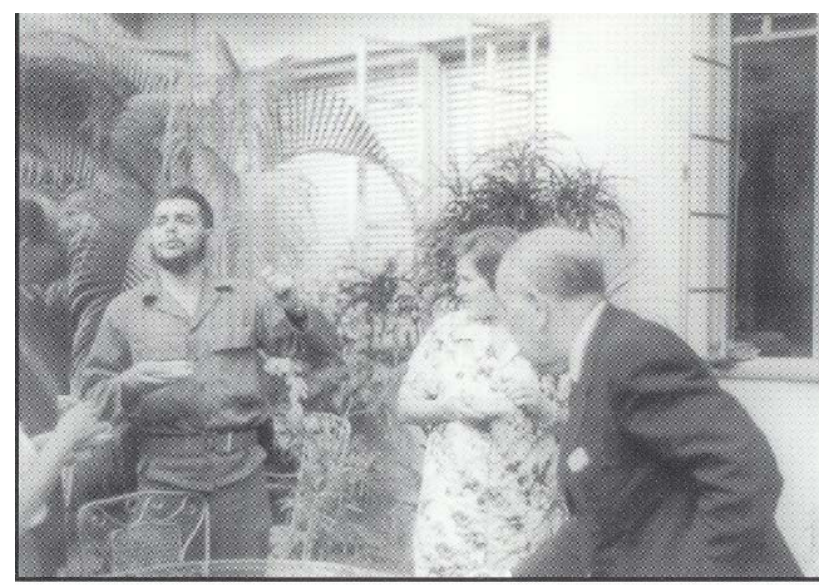

1962 - En La Habana, Cuba, con Ernesto "Che" Guevara.

Imagen publicada en Universidad de Guadalajara 1993: 90

posicionamientos públicos de Orfila Reynal frente al imperialismo norteamericano apareció en dos artículos en los que asoció el proyecto de la Franklin Publications Inc. con una clara ingerencia de la Alianza para el Progreso sobre la industria editorial latinoamericana. En octubre de 1961, representantes de la Franklin Publications Inc realizaron una gira latinoamericana para entablar acuerdos con grandes editores y representantes del sector editorial de la región. Dicho «organismo educativo, no comercial» lo componían representantes de las mayores empresas editoriales y de dependencias del gobierno de los Estados Unidos. Divulgaban su misión como una contribución técnico-profesional y económica para el desarrollo de los mercados del libro. Legitimaban su obra con sus logros asiáticos. ${ }^{31}$ Luego de recibirlos en el FCE y de leer los documentos internos de la Franklin, Orfila Reynal concluyó que detrás de la "cooperación» decantaba un plan de colonización cultural. Lo que aportaba la Franklin era, en última instancia, un sistema de créditos a bajo interés para la traducción de autores norteamericanos:

«Anotada la circunstancia de que este estudio se presentaba como un prolegómeno a la acción que habría de cumplirse para poner en marcha la Alianza para el Progreso, muchas mentes fantasiosas (y comerciales) imaginaron que parte de la promesa de los 20 mil millones de dólares que los latinoamericanos acogieron con lágrimas en los ojos en Punta del Este, se volcaría sobre la sufrida industria editorial para hacerla tan 'vigorosa y original' como lo desean ardientemente los editores y gobernantes de los Estados Unidos» ${ }^{32}$

Tres meses más tarde, La Gaceta dio lugar para una réplica de los directivos de la Franklin Publications. Allí retrataban el «ataque amargo y sarcástico de una respetable fuente del sur de la frontera, el Doctor Orfila, un muy influyente editor de América Latina», como «una muestra muy acentuada de orgullo nacional». ${ }^{33}$ Orfila cerró el diálogo con otro texto en el que denunció: «se puso el dedo en la llaga»; es decir, la acción de la Franklin hería como violencia física. Para tolerarla, exigía que Estados Unidos abriera el interés en su propio territorio hacia la extensa producción intelectual y editorial latinoamericana, condición para la «posibilidad de diálogo igualitario que abre los caminos de una colaboración libre y justa». ${ }^{34}$ Después de 1965, las declaraciones de Orfila en la prensa muchas veces rompieron la mesura de su distinguida postura, para protestar enfáticamente contra el imperialismo yanqui y la colonización del pensamiento de los escritores e investigadores del continente, impuesta dulcemente con becas y programas de financiamiento a la educación superior que bajaban desde el norte.

\section{Los hijos de Sánchez}

La excusa para iniciar el proceso de destitución de Orfila Reynal fue la publicación de Los Hijos de Sánchez de Oscar Lewis. En la visión de algunos intelectuales, académicos, periodistas y políticos mexicanos, este libro ofendía su cultura nacional al proponer una teoría sobre «la cultura de la pobreza», apoyada en testimonios plagados de un vocabulario "soez» al respecto de la naturaleza de la política, la violencia y el desarrollo mexicanos. Las críticas al libro de Lewis y a la actitud de Orfila al permitir su edición, explotaron como el resultado de un contenido proceso de indignación por parte de sectores culturales y políticos conservadores, hacia ciertos libros que estaban siendo publicados bajo el mando de Orfila. Este malestar se habría iniciado al menos desde abril de 1961, cuando apareció Escucha yanqui, del sociólogo Charles Wright Mills. En otras palabras, Los hijos de Sánchez fue la gota que colmó el vaso de la paciencia para los intelectuales más conservadores ligados al poder. La reacción contra Orfila fue una embestida contra el extranjero que, al mando de una empresa apoyada por el Estado, promovía libros sino revolucionarios, por lo menos críticos o «subversivos» para los estandartes de una moral nacional, occidental, cristiana. Los avatares de la edición del libro de Wright Mills permiten restituir la secuencia de algunos de los hechos y representaciones más significativos que desencadenaron en el affaire Orfila.

Escucha yanqui fue un libro editado en los Estados unidos en 1960 y un año después por el FCE. ¿Por qué una edición de cuatro años de existencia se sumaría a los embates contra Orfila Reynal de 1965? Escucha yanqui era el testimonio de un radical preocupado por caracterizar en la propia Cuba, las motivaciones y objetivos de los revolucionarios. No era un estudio situado en México como Los hijos de Sánchez. No implicaba, 


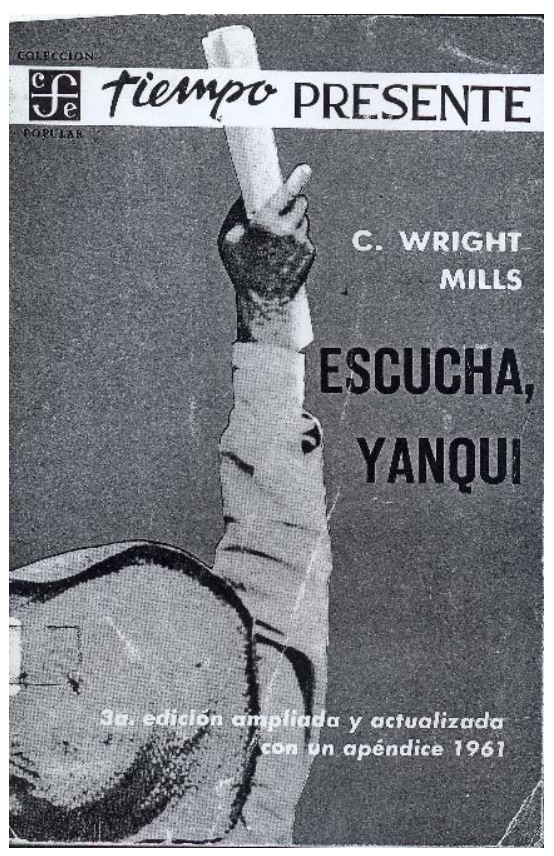

necesariamente, un daño moral hacia la nacionalidad mexicana. La mención de este libro en el episodio de renuncia de Orfila, significaba, tal vez como ningún otro título, el control ideológico que los Estados Unidos aplicaban sobre la circulación de ideas «subversivas» a través de la compleja red de subordinaciones y mediaciones con las que la Alianza para el Progreso marcó presencia en el escenario de la cultura impresa en América Latina.

Para las autoridades que promovieron la destitución de Orfila, Lewis y Mills eran en extremo desviantes: ambos gringos; uno capaz de mostrar las contradicciones del desarrollo mexicano frente a la fuerza integradora de la tradición (problema boasiano por excelencia); el otro, un sobreviviente del macarthismo con credenciales de Columbia, capaz de introducir visiones positivas de la revolución cubana en propio territorio norteamericano. Ese binomio editorial articulaba los argumentos nacionales e internacionales de una decisión claramente política para orientar los rumbos de la cultura oficial mexicana. Podrían soportarse estudios críticos de autores latinoamericanos o europeos, pero no de gringos, con todo lo que significa esta categoría social en la historia política y cultural mexicana. Insisto, yanquis de impresionante resonancia pública, mirados como "panfletistas» que revelaban aspectos positivos de la pobreza (o la marginación) y la revolución; cuestiones que, desde una mirada pro-alianza para el progreso, eran consideradas barreras al desarrollo nacional y «occidental». ${ }^{35}$

Escucha yanqui inauguró la serie «Tiempo Presente» de la Colección Popular, junto a otros cuatro libros con los cuales formó sistema: El reto de África, de Ndabaningi Sithole (pastor anglicano negro de Rodhesia); Yugoslavia, democracia socialista, de Jovan Djordjevich (profesor universitaria y consejero de Estado), La china popular y su economía, de Hughes y El Estado del futuro, de Myrdal. La serie se encuadraba en un nítido horizonte tercermundista. En abril de 1961, fue presentada en La Gaceta, número 78. La nota de portada estaba firmada por Charles Wright Mills: «Una política civilizada para la revolución de las naciones hambrientas». ${ }^{36}$ Escucha yanqui sobresalía en esa serie por el renombre del autor y por la consagración del libro en su país de origen: fue lanzado en Nueva York el 28 de noviembre de 1960 y se vendieron 338.000 ejemplares en 40 días. La publicación por el FCE también fue un impresionante éxito de ventas: la primera edición, lanzada en abril de 1961, se agotó en un mes y la tercera edición de agosto del mismo año se realizó con una tirada de 70.000 ejemplares. Esta última salió al público junto a la edición de otro libro de Wright Mills: La imaginación sociológica. ${ }^{37}$

En los primeros años sesentas, entre las notas de La Gaceta resaltaban las referidas a los dilemas políticos del Tercer Mundo, incluyendo reseñas o textos de académicos e intelectuales norteamericanos: por ejemplo, en el número de Mayo de 1961, se transcribió una nota sobre América Latina de Samuel Schapiro, economista de Columbia. Durante todo el año 1961, las páginas del periódico La Gaceta privilegiaron la publicidad de la Colección Popular. Escucha Yanqui y la obra de Wright Mills fueron objeto de varias reseñas y trabajos alusivos. Estos comentarios y publicidad cerraron un ciclo hacia abril de 1962, cuando se notició la muerte del sociólogo norteamericano a los 46 años: en la semblanza, Mario Monteforte enunció el marco de significación que dominaba la recepción de Mills: «con Escucha Yanqui, por su alegato a favor de la justicia de la Revolución cubana, Mills se incorpora a la familia de nuestros grandes panfletarios que en días de ira señalan culpables y esperanzas para el futuro de los pueblos oprimidos (...) Ya era difícil juzgar desde el punto de vista científico a ese militante de una solitaria ideología, a ese crítico despiadado de la sociedad que nosotros también resentimos» (cursivas mías). ${ }^{38}$

Es éste el marco que engloba la edición en 1961 de Antropología de la pobreza, el primer libro de Oscar Lewis editado en castellano por el FCE. A diferencia de Escucha Yanqui, ese título fue incluido en la Sección Antropología. En principio, digamos, animaba esta edición un criterio académico. Durante el proceso de la Procuraduría en su contra, Orfila recordó que la publicación de Lewis fue decidida luego de compartir con el autor extensas sesiones de audición de los registros de campo y de corroborar la consagración de las novedosas técnicas de Lewis (p.e.: a day in a life) en importantes foros internacionales de las ciencias sociales de la época. En la nota de portada del número 85 de $L a$ Gaceta (septiembre de 1961) en la que se anunciaba Antropología de la pobreza, aparece una 

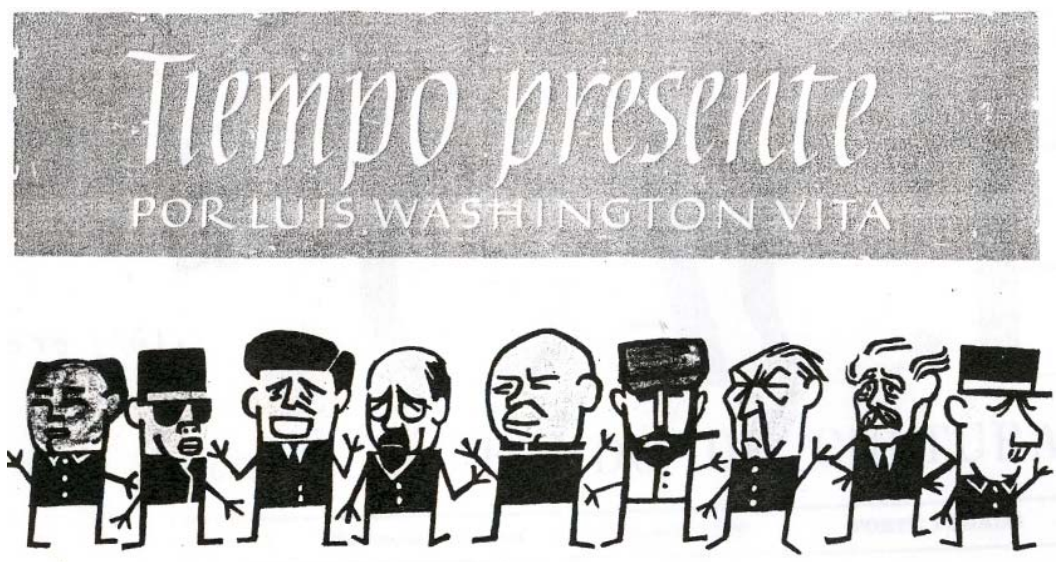

Dibvios de Boudewiin J. B. Letswoort

Publicidad de la colección Tiempo Presente aparecida en La Gaceta nº 85 (Septiembre 1961).

entrevista de Héctor Chávez donde Lewis exponía los objetivos de su trabajo:

«Me propuse ofrecer un cuadro íntimo y objetivo de la vida diaria de cinco familias mexicanas -originarias de un mismo pueblo del interior y migrantes a la ciudad de Méxicocuatro de las cuales obtienen ingresos alarmantemente bajos. Me propuse asimismo contribuir a la comprensión de la pobreza en México de hoy día y, en tanto que los pobres de todo el mundo tienen algo en común, a la comprensión de la vida de la gente pobre en general».

En caja de grandes letras, los editores de $L a$ Gaceta resaltaron las consecuencias políticas de este estudio: «Aunque el bienestar de México ha aumentado, dice, su desigual distribución ha permitido que la disparidad entre los ingresos del rico y los del pobre sea aún más aguda que en épocas pasadas». The children of Sánchez. Autobiography of a Mexican family de Oscar Lewis, había sido publicado por Random House de Nueva York en 1961. Su lanzamiento por el FCE fue en octubre de 1964. A juzgar por la aparición de una segunda edición en diciembre del mismo año, el libro fue un éxito de ventas.

\section{Los hijos de Kafka}

Para personas como Gustavo Díaz Ordaz, Salvador Azuela o Luís Cataño Morlet, Orfila era el eje de articulación de una extensa red cultural y política que abarcaba ambos extremos del Atlántico y unía un segmento dominante de la intelectualidad progresista de posguerra. Un golpe en ese centro afectaría al conjunto. El día 9 de febrero de 1965, Cataño Morlet condenó Los hijos de Sánchez como obra obscena y denigrante para el país, durante una conferencia dada en la Sociedad Mexicana de Geografía y Estadísticas a la que asistió Díaz Ordaz. Cataño Morlet era juez de la Suprema Corte de Justicia de la ciudad de México, diplomático y presidente de la SMGE. Parte del auditorio apoyó sus críticas y como resultado se resolvió por votación que dicha institución movilizara acciones legales contra el autor y el editor. ${ }^{39}$ Dos días después se presentaba una denuncia en la Procuraduría General de la República, la cual pasó a tomar declaraciones a los denunciantes y al director del FCE. Fue amplia la repercusión periodística ante estos hechos. Pero el 6 de abril, el Ministerio Público se abstuvo de iniciar acciones penales al considerar que no había delito a perseguir. ${ }^{40}$ Ante el revés judicial, la SMGE siguió con su plan de desplazamiento de Orfila Reynal por los canales de la alta política. El 7 de noviembre, el editor fue citado por Jesús Rodríguez y Rodríguez, subsecretario de Hacienda de la nación. En calidad de «miembro propietario» de la Junta de Gobierno del FCE, allí le solicitó el cargo, aparentemente por su condición de extranjero. ${ }^{41}$ Al día siguiente Rodríguez y Rodríguez llegó a la editorial acompañado por «el Licenciado» Salvador Azuela, el nuevo director. La actitud de Orfila fue de aplomo y mesura: agradeció a los funcionarios y empleados, recorrió las instalaciones con Azuela y planearon los plazos de su alejamiento, lo que incluía el abandono en 24 horas del departamento que ocupaban el editor y su mujer en el predio de la editorial. Al interior de la empresa, el cambio de mando produjo un generalizado sentimiento de indignación:

«Eso fue de lo más dramático que he vivido en mí vida -recuerda Martí Soler-. Fue un momento sorpresivo para nosotros. Orfila posiblemente lo sabía de un día o dos antes. No mucho más. Supo que lo iban a dimitir y nos llama a todos. Estaba un representante de Hacienda y nos dice que Orfila va a dejar de ser desde ese momento el Director, y que el señor Azuela pasaba a ser el nuevo director. Eso nos agarró a todos en frío... Y entonces empezó el escándalo periodístico que debes 
saber. Varios empleados deciden boicotear el asunto y hacen que los echen. Uno de ellos, Jas Reuter, se instituye en nuestro líder. El día que el señor Azuela llegó al Fondo hizo que cambiaran la cerradura de todas las puertas, de todas las dependencias, porque nos consideraba una pandilla de ladrones. Yo no me lo explico. Que tuviera diferencias desde el punto de vista político o lo que sea, pues bueno, muy bien. Él mandó a hacer una auditoria de todo, y por supuesto no encontró nada. No sé quién le había metido esa idea en la cabeza» (Martí Soler, entrevista).

La tensión generada internamente por numerosos empleados llevó a una seguidilla de despidos para los cuales la empresa tuvo que utilizar un cuarto del presupuesto anual de 1966 en materia de indemnizaciones.

Salvador Azuela era hijo del reconocido escritor Mariano Azuela. Este único dato basta para evidenciar su proximidad con el FCE. ${ }^{42}$ Mantenía estrecho vínculo con Gustavo Díaz Ordaz: ambos se conocían al menos desde los años 40, cuando Ordaz era senador y Salvador Azuela Director de la Facultad de Filosofía y letras de la UNAM. Este vínculo habría continuado en los años 50, cuando el primero era secretario de Gobernación y el segundo director del Instituto Nacional de Estudios sobre la Revolución Mexicana, del que fue fundador y en donde realizó algunas tareas de edición. No tardó Azuela en manifestar su desacuerdo con la orientación cultural y política de la editorial. En octubre de 1966 renunciaron a la junta de gobierno los miembros fundadores que quedaban: Gonzalo Robles, Eduardo Villaseñor y Emigidio Martínez Adame. En diciembre de 1967 se alteró el estatuto del fideicomiso para posibilitar el control directo del FCE por parte del Ministerio de Hacienda a través de un Comité Técnico compuesto por Jesús Rodríguez y Rodríguez, Salvador Azuela, Francisco Monteverde y Víctor Urquidi. El fin del mandato de Azuela, coincide con un nuevo cambio en la presidencia de la nación, evidencia nítida del tenor heteronómico que tuvo la llegada de Azuela al FCE: en 1970 asumió el presidente Luís Echeverría Álvarez y el secretario de Hacienda Hugo Margáin designó a Antonio Carrillo Flores al frente del FCE. Éste buscó rescatar el proyecto original y restituyó la Junta de Gobierno. Sin embargo su gestión duró apenas un año y medio. El catálogo buscó ser mexicanizado, acción guiada por la creación de la colección Vida de México.

Los nombres de Díaz Ordaz y de Echeverría, los dos presidentes de la República aquí mencionados, bastan para clasificar el affaire Orfila como el primer evento entre tantos que marcaron la guerra fría y la guerra sucia en el México de los años sesenta. Recientemente fueron revelados los detalles de la Operación Litempo que la CIA ejecutó en México durante los años 60. Fue descubierto así que ambos políticos habrían sido agentes de la CIA norteamericana desde fines de los años $50 .{ }^{43}$ El objetivo de la Operación Litempo era reclutar a altos funcionarios mexicanos para la inteligencia norteamericana contra los avances del comunismo. Este programa estuvo a cargo de Winston Scott, quien en 1956 reclutó a Emilio Bolaños, un sobrino de Díaz Ordaz quien pasó a ser clasificado como Litempo 1. Ese mismo año fue reclutado Gustavo Díaz Ordaz como Litempo 2. Luís Echeverría Álvarez fue Litempo 8. Para ese entonces, Díaz Ordaz era uno de los principales dirigentes del ala conservadora del PRI. Había nacido en Puebla en 1911 y obtenido el título de abogado por el Colegio del Estado de su ciudad natal en 1926. Desde 1943 ocupó altos cargos políticos como diputado y senador nacional. Entre 1958 y 1963 fue Secretario de Gobernación durante la Presidencia de Adolfo López Mateos. Inició su mandato presidencial el $1^{\circ}$ de diciembre de 1964. Al tiempo que profundizó el desarrollo económico basado en el petróleo y la industrialización, mantuvo políticas sociales beligerantes e intransigentes. Se enfrentó a numerosas corporaciones, como los médicos, y bajo su mandato se produjo la matanza de estudiantes en la plaza de Tlatelolco, poco antes del inicio de los Juegos Olímpicos de México, en 1968. Durante todo su mandato fue permanente la guerra sucia contra organizaciones políticas de oposición y guerrilleras. Luís Echeverría Álvarez, por su parte, era el Secretario de Gobernación de Díaz Ordaz, lo cual está en sintonía con la génesis política de estas decisiones.

Las expresiones de reprobación o apoyo a Orfila se extendieron hasta la sustitución de Salvador Azuela por Antonio Carrillo Flores, a finales de 1970. El escándalo aparecía como un evento eficaz para la mutua demarcación de posiciones polares en los ámbitos de la cultura y de la política. En 1967, por ejemplo, Orfila fue invitado por la Universidad de Chile para dinamizar un proyecto editorial similar a Eudeba. Allí conoció a Salvador Allende y su presencia motivó amplia repercusión, tanto por el relato de los sucesos del despido como por sus manifiestos lineamientos políticos y culturales. Sus declaraciones colmaron la indignación de Azuela:

«La presentación del señor Arnaldo Orfila Reynal, argentino que se hizo presentar durante su gira como mártir de la libertad y perseguido político del Gobierno de México, atacó a éste y a la Junta de Gobierno, atribuyéndoles su cese al publicar Los hijos de Sánchez, lo que es una solemne mentira» (declaraciones de Salvador Azuela publicadas en La Prensa, México, 13 de octubre de 1967).

Para revertir las razones, Azuela presentó los resultados de un informe financiero que legitimaba la «dimisión» de Orfila por mala administración. 
En un comunicado de prensa fechado el 12 de octubre de 1967, Salvador Azuela informaba que «había recibido la empresa en bancarrota». La empresa adeudaba 2.536 .000 pesos de compromisos sin saldary por derechos de autor. Asimismo se informaban las altas sumas de dinero gastadas en indemnizaciones a Orfila (560.000 pesos) y a otros 19 funcionarios que recibían «retribuciones especiales». La nota firmada por M. Mondragón remataba con el tono de una moraleja cuyos esquemas invariantes fueron frecuentes en la expresión de opiniones sobre la relación entre intelectuales extranjeros y el Estado mexicano:

«El caso de Orfila, dicen varios literatos, es uno más de un extranjero que obtuvo pingües ganancias y sólo responde a la hospitalidad y generosidad de México con ingratitud (...) Los hechos concretos que señalo -dice el licenciado Azuela- revelan la veracidad y el valor civil de Orfila que, agresivo en América del Sur, en México se retracta y adula en público, mientras se embosca para atacar a mansalva. Con estos datos puede juzgarse la probidad de su conducta». ${ }^{44}$

El gobierno de Díaz Ordaz mantuvo una férrea vigilancia sobre la prensa y dominó importantes empresas periodísticas. ${ }^{45} \mathrm{El}$ tono de los embates contra Orfila parece corroborar ese clima en las batallas por la información: «No podemos dejar de escribir sobre los esfuerzos editoriales que se continúan haciendo en México y, sobre todo, del lado del Fondo de Cultura Económica, la importantísima empresa editorial que fue rescatada de las manos de un comunizante argentino -Orfila-, para ser dirigida, ahora, por el licenciado Salvador Azuela, cuya honradez intelectual es bien conocida desde sus tiempos de estudiante y a lo largo de todo su fecundo vivir», escribía Bernardo Ponce en las páginas de El sol de México, el 5 de enero de 1968.

\section{Los hijos de Orfila}

El 7 de noviembre de 1965, al salir de la reunión con Rodríguez y Rodríguez, Arnaldo se encontró sorpresivamente con el periodista Deschamps. ${ }^{46}$ Le relató el episodio del despido y Deschamps lo comunicó en primera plana del diario Excelsior de la mañana del día 8. La noticia corrió como reguero de pólvora. Al finalizar ese día, 70 amigos se dirigieron al departamento de Orfila y Séjourné. Se destacaban intelectuales como Elena Poniatowska, Fernando Benítez, Guillermo Haro, Jesús Silva Herzog, Pedro González Casanova. Entre todos, al cerrar la jornada, acordaron un plan para fundar una nueva editorial. Orfila propuso el nombre Siglo XXI que reservaba para un proyecto de revista que nunca salió a luz y calculó que para ello haría falta, al menos, un millón de pesos mexicanos. Se propuso armar una sociedad anónima con accionistas dispuestos a no reclamar dividendos, sólo a exigir que toda ganancia se invirtiera en proyectos de edición. Quince días después, se organizó una cena en el Club Suizo a la que asistieron 300 personas que pagaron 100 pesos cada una. Los amigos argentinos de Orfila juntaron dinero para que allí pudiera representarlos el historiador José Luís Romero. Tres meses más tarde se creaba formalmente la editorial Siglo XXI. En semanas la red se amplió a cerca de 600 accionistas. El capital inicial rondó los 250.000 dólares.

A las 24 horas del despido, la corriente de solidaridad con Orfila se articuló en una red epistolar que atravesó el continente hacia el sur y cruzó al Atlántico, con la comunicación entre una comunidad de escritores latinoamericanos radicados en Europa. A través de la misma se puede recuperar un estado de sensibilidad frente al acontecimiento, representaciones y acciones del momento. Carlos Fuentes, por ejemplo, así le expresaba su solidaridad a Orfila:

«Gracias a nuestra amiga Nora Velasco y a un artículo de Deschamps en Excelsior, me entero hoy del atraco infame e infamante que acaba de cometerse en el Fondo. Quiero hacerle llegar de inmediato mi sentimiento de solidaridad con usted como persona, como amigo, como intelectual, mi solidaridad con la obra que usted ha realizado en nombre de todos nosotros, de cada uno de nosotros como escritores y en nombre de toda nuestra comunidad hispanoamericana -que en gran medida puede hoy poseer esos atributos de organismo cultural vivo gracias a la generosidad y la visión con que usted la cultivó, la reunió, le dio conciencia en mil ocasiones vivas-, indignación por el procedimiento típicamente fascista que se usó para destituirlo, para negar -ingenua aunque tenebrosamente- el homenaje permanente que usted merece de parte de la cultura en lengua española, con un ruin y frío expediente burocrático, para advertir, en fin, que la independencia intelectual corre muy serios peligros en nuestro país, amenazado por las górgonas del conformismo, la uniformidad, la auto celebración o el simple fiat despótico de una mancuerna de politicastros corruptos. Los hijos de Kafka, mi querido doctor, se han vengado de los hijos de Sánchez.

No sabría insistir lo suficiente, en este momento, en la convicción que me acompaña al escribirle: la convicción de que los mejores, los auténticos intelectuales de América Latina y del mundo, están con usted y lo seguirán acompañando (...) Por favor dígame cómo puedo ayudar; sé que estamos, nuevamente 
en una batalla por mantener viva la libertad intelectual en México y en América Latina y quiero que usted y todos nuestros amigos, los mejores y más leales, Fernando, Vicente, Elena, José Emilio, Julieta, Enrique, Víctor, Laurette, cuenten conmigo sin condiciones, sin consulta previa, permanentemente en todo lo necesario para ganar esta batalla.» (C. Fuentes a Orfila Reynal, desde Roma, 16/11/65).

El mismo día Fuentes le escribió al mencionado Vicente para pedir consejos para sacar sus libros del FCE:

«no quiero seguir ni un minuto más en esa Gestapo de la mediocridad que se ha instalado a la Hitler en el Fondo -y de cuya honorabilidad me permito, en más de un sentido, dudar seriamente- (...) Para no continuar con lo del Fondo, que me hace hervir la sangre de furia, díganme si desde aquí puedo mandarles opiniones de gente como Neruda, Asturias, Vargas Llosas, Cortázar, Alberti, etc., sobre Orfila, para el Suplemento (de La cultura en México) (...) ¿Me equivoco al pensar que, a la mexicana, esta ha sido la respuesta, y la advertencia, de la clique Urchurtu - Ortiz Mena por 'Los Hijos de Sánchez’?»

Era tal la sintonía de Fuentes con el proyecto de Siglo XXI, que el 2 de junio de 1966 le expresaba a Orfila que Zona Sagrada, su próxima novela para la editorial, sería una especie de Antropología de la riqueza:

«Su marco social es el de la cultura de la abundancia en México, el otro lado de 'las cinco familias', para seguir con la relación Lewis. Pero de allí parte a un mundo fantástico en el que la Actriz es Madre, Hechicera, Amante, Circe, Transfiguradora. El mundo de la Edad Media encuentra el mundo de Vogue Magazine. Los delfines de la generación posterior a Artemio Cruz entran a habitar el clima y las mansiones de Aura.»

Cada uno de los intelectuales que mostraron lealtad a Orfila, fue sondeado para participar como buscadores de novedades entre la vanguardia cultural y política europea y latinoamericana de esos años. ${ }^{47}$ El 27 de junio de 1966, por ejemplo, Orfila le solicitó a Fuentes que se acercara a Claude Gallimard y a Ugne Karvelis, «quienes le habían ofrecido su mayor ayuda y simpatía a Siglo XXI», y acelerara la contratación de Les mots et les choses de Michel Foucault, libro por el cual Orfila había pagado un adelanto de mil dólares. Fuentes, Cortázar, Pellicer, Rulfo, Carpentier, y muchos otros se dispusieron a clausurar contratos con el FCE y depositar todas sus obras en Siglo XXI. Otros como Vargas Llosas y Asturias también propusieron pasarse al catálogo de Siglo XXI, desde sus editoriales argentinas. Esta carta blanca le hubiera permitido a Orfila monopolizar la edición del núcleo central de lo que fue considerado el boom de la nueva narrativa latinoamericana. Sin embargo, decidió que Siglo XXI no reeditara ninguna obra. Sólo se dispuso a publicar libros en primera edición. La siguiente descripción de Carlos Monsiváis permite sintetizar las apuestas centrales del catálogo que Siglo XXI armó de allí en más:

«En su etapa inicial Siglo XXI es la editorial que promueve algunas de las tendencias más notorias del período marcado por la Revolución Cubana, el nuevo pensamiento latinoamericano, el boom de la narrativa, el pasmo ante la teoría de la dependencia, el auge y el fracaso trágico de la guerrilla continental, la emergencia de la Teología de la liberación, los nuevos métodos de enseñanza omunitaria, las revisiones del marxismo. Siglo XXI publica a Pablo González Casanova, Paulo Freire, Poulantzas, Lacan, Marta Harnecker, Ios revolucionarios centroamericanos, los clásicos del marxismo, la sociología argentina (...) Durante una década, los grupos y partidos de izquierda, las comunidades eclesiales de base, los estudiantes de ciencias sociales, los nacionalistas revolucionarios, los descontentos con las situaciones de miseria y explotación, acuden al acervo de Siglo XXI para informarse, para crearse un horizonte de expectativas revolucionarias, definir y redefinir el sentido de su acción» (Monsiváis 1993: 35)

Sin lugar a dudas, Siglo XXI dominó la edición de obras de vanguardia de ciencias sociales, de política y parcialmente de literatura entre, al menos, 1965 y 1975. Una acción editorial que, gracias a la singularidad de sus capitales de origen y al trabajo articulado en un triangulo de subsidiarias asentadas entre México, Madrid y Buenos Aires, tuvo efectos sobre toda América Latina. Fue, tal vez, la última batalla por establecer una cultura común y universal entre lectores de naciones periféricas.

\section{Conclusiones}

La difusión de los impresos y el desarrollo de mercados editoriales proporcionan, de modo similar a la estructura del sistema educativo y a la cuestión de la alfabetización, índices concretos sobre la composición y el alcance de las esferas públicas y los campos de poder. Arnaldo Orfila Reynal fue atacado como un agente central entre aquellos que a partir de los años 50 buscaron democratizar la cultura del libro en un país con profundas divisiones sociales, cuya esfera del 
poder, centrada sobre el PRI como partido único del y para el poder, fue históricamente disputada entre «maestros»y «licenciados». Hasta la asunción de Orfila como director de la casa matriz, el FCE se había orientado, prioritariamente, a la formación de un estamento: los expertos, agentes preparados para guiar el pensamiento, la ampliación del público lector, los rumbos de México, con el instrumental más avanzado de las ciencias y la educación superior. La formación de economistas, o de intelectuales atentos a las novedades de la ciencia política, la sociología, la antropología (disciplinas que recién se profesionalizarían en los años 50), era guiada por una esperanza modernizadora. Dos factores internacionales, sin embargo, ampliaron el radio de acción del FCE: Ios exiliados republicanos españoles y la conexión con el resto del sub-continente a través de proyectos intelectuales y editoriales americanistas. Hasta cierto punto, creo haber demostrado, del exterior se introdujeron innovaciones que en determinada coyuntura provocaron contradicciones que irían a alterar las estructuras del espacio editorial mexicano y de las relaciones entre los intelectuales y el poder, el Estado.

En el México de los años 40, el mercado editorial era predominantemente restringido. Sin embargo, en el resto de los países hispanoamericanos, pero también en el Brasil, había un nicho vacío para la clase de libros producidos por el FCE. Es por ello que el crecimiento y la consagración de esta editorial fue producto del encuentro entre factores nacionales e internacionales en materia de libros y lectores. ${ }^{48}$ Es una razón más para comprender por qué es México el país donde más enfáticamente se diseñaron proyectos para construir representaciones sobre América Latina. Así como el drama español y los transterrados señalaron el rumbo para pensar América (Latina) y proyectar ese realidad como espacio cultural y como mercado editorial de interdependencias nacionales, no es casual que fuera un extranjero quien hacia fines de 1940 estuviera al frente del cambio de rumbo en el catálogo del FCE hacia su mexicanización y hacia la conquista de un público lector masivo. Esos extranjeros buscaron recrear el aire que habían respirado en las dinámicas esferas públicas de sus países de origen, sobre un espacio social estamentario, una sociedad fuertemente jerárquica, un orden social que hizo lugar para el desarrollo de sus proyectos, aunque bajo condiciones controladas. ${ }^{49}$

Limitar esos cambios a la sola presencia de Arnaldo Orfila Reynal sería un peligroso reduccionismo. Su trayectoria, sin embargo, conjugaba múltiples propiedades para que esos cambios fueran posibles. Desde el colegio secundario se impregnó de las perspectivas que la esfera pública argentina ofrecía para la realización de experiencias editoriales, de educación obrera, de acción política, de internacionalización, de vanguardismo cultural. Orfila aparecía como una persona situada en el momento y lugares precisos entre algunos de los acontecimientos de mayor trascendencia en la historia política e intelectual de América Latina: la reforma universitaria argentina, el congreso internacional de estudiantes de México, las vanguardias de los 20, la guerra civil española, gerente de un emprendimiento central para la afirmación de la cultura mexicana, referente de y para la revolución cubana, epicentro del primer combate de la guerra fría cultural en suelo mexicano, director de un proyecto editorial que dominó las vanguardias políticas e intelectuales de los años 70. Orfila Reynal vivió 100 años. En la última década de vida, su estado de salud lo salvó de sufrir la crisis desatada en la izquierda occidental, y por lo tanto en la editorial Siglo XXI, al caer el muro de Berlín. La longevidad vital fue acompañada por una jovialidad estructural. Esta fue sostenida por fuertes experiencias sociales y periódicas reconversiones en su trayectoria que contrarrestaron la rutinización de su carisma. Fue preso como huelguista del 18; opositor al régimen conservador de los años 30 y al primer gobierno peronista; migró a México en un momento de derrota para la fracción de elite intelectual que lo incluía, la misma que, una vez consagrado como gran editor en México, lo llamó, tras el derrocamiento de Perón, para fundar un proyecto (Eudeba) que renovara la centralidad de Argentina como «centro editor de América Latina»; sucedió a Victor Sèrge como marido de Laurette Séjourné; fue referente para la legitimación internacional de la Revolución cubana; fue primera víctima de la guerra fría cultural y por ello emblema para el agrupamiento de las vanguardias literarias, universitarias y políticas de izquierdas en los años 60 .

Las condiciones sociales, intelectuales, editoriales y políticas que llevaron a Orfila Reynal a ocupar la dirección del FCE fueron causa y consecuencia de las novedades que canalizó en calidad de importador. El reconocimiento a su labor por la iluminación de la producción intelectual mexicana, por el afianzamiento de la proyección internacional del sello y por la conquista de un público masivo, asentaron un habitus carismático y patriarcal que atraía un ejército de escritores, editores, lectores que reconocían su nombre como centro de los proyectos de modernización cultural y radicalización política de finales de los años 50 . Ese poder delegado explica su audacia para difundir, a través de una empresa amparada por el Estado mexicano, el pensamiento político internacional que legitimó las revoluciones del Tercer Mundo. Así pasó la raya de los parámetros éticos y morales espectados en las esferas del poder mexicano. De allí que un extranjero fuera el blanco más estratégico para el asalto a la 
máxima fábrica de la cultura nacional impresa, por parte de cierta fracción de la elite cultural ligada a la derecha del PRI, en un momento donde la acción política obedecía a condicionamientos internacionales típicos de la Guerra Fría.

Desde la superficie del escándalo, la crisis descendió hasta trastocar estructuras del mercado editorial en particular y del campo de poder como un todo. La centralidad que pasó a ocupar la editorial Fondo de Cultura Económica en México desde mediados de los años 40, condicionó en gran medida el perfil del mercado editorial nacional: su magnitud inhibió la proliferación de múltiples concurrentes al punto que sería posible formular la pregunta sobre la relación entre un Estado de partido político único y un mercado editorial no digamos de editorial única, pero al menos hegemonizado por un solo sello paraestatal. Si bien aquí no se presentó un estudio del espacio editorial mexicano en su diversidad y luchas de concurrencia, es preciso afirmar una hipótesis que guiará próximos trabajos: la crisis desatada por el affaire Orfila Reynal resquebrajó la hegemonía del FCE, posibilitó la diversificación del espacio editorial y lo dotó, finalmente, de una estructura de campo. Demostrarían este proceso la influencia que hacia mediados de los años 60 pasaron a ejercer Siglo XXI en la publicación de ciencia social y política, así como Joaquín Mortiz y Era en literatura y ensayística.

Que tales acontecimientos hubieran estallado en el medio editorial confirman la significación que la publicación de impresos puede tener para la génesis de la esfera pública y las transformaciones de la cultura y la política. El estudio revela que esa significación no es una razón necesaria o evidente. Lo que el escándalo hizo saltar fueron estructuras y relaciones previamente construidas y sublimadas en el ritmo de la vida cotidiana de la edición y las prácticas intelectuales, literarias, políticas. Las características del affaire Orfila, la historia de las relaciones sociales y simbólicas que puso en juego muestran una variante posible entre la clase de experiencias en las cuales el medio editorial puede ser teatro de acciones políticas. El medio editorial construye un espacio de publicidad. No sólo por la difusión de ideas impresas sino también por sus posibilidades para reunir productores culturales individuales en proyectos colectivos. Ésta propiedad se agudiza cuando factores heteronómicos amenazan la vida en los espacios que «normalmente» regulan la vida literaria, académica, literaria, científica. Así parecen haber reaccionado los intelectuales mexicanos que apoyaron a Orfila en un momento en el que la guerra sucia y la cultura oficial imperante durante la era Ordaz - Echeverría, los excluía por censura o por el peligro de verse asociados con representaciones que amenazaban los fundamentos más cristalizados de las ideas de intelectual, escritor o artista. Los testimonios de Fuentes se entrelazarían con los de Cortázar, Carpentier, Paz, Asturias y un «ejército de intelectuales» que le manifestaron a Orfila, a través de centenares de cartas, que él fue un catalizador para su autorepresentación como comunidad intelectual y para la imaginación de «una cultura latinoamericana». Esa función de representación fue desarticulada a fuerza de golpes militares.

La crisis de 1965 renovó la juventud estructural de Orfila, quien gracias al impulso colectivo e internacional de Siglo XXI, hacia finales de los años 60 era reconocido por gran parte del mundo editorial occidental como exponente mayor del espacio iberoamericano del libro. A pesar de todo esto, la historia de Orfila Reynal no fue escrita. En los ensayos sobre la reforma universitaria, por ejemplo, su figura queda opacada tras la de los intelectuales o escritores de ese movimiento, como Deodoro Roca en Córdoba o Héctor Ripa Alberti en La Plata. Son los nombres de autor, los que pueden fundar discursos y marcar épocas. En los raros casos en los que la historia retiene el nombre de un editor, se exige la extensión de su función hacia la de un intelectual. La visibilidad alcanzada por Orfila Reynal desde finales de los años 50 permitió su representación como un líder cultural ejemplar. Desde entonces no es raro hallar comentarios que lo señalan como «el fundador» del Fondo de Cultura Económica. ${ }^{50}$

\section{Cabana, septiembre de 2008}

\section{Agradecimientos}

Quiero expresar mi agradecimiento a quienes me autorizaron a tomar registros el archivo y la biblioteca del Fondo de Cultura Económica y el acervo histórico de Siglo XXI. También a Martí Soler, Ricardo Nudelman, Jaime Labastida, Tatiana Coll, Esperzanza Rascon, Horacio Crespo, Carlos Díaz y todas las personas que me auxiliaron y/o se dispusieron a ser entrevistadas durante dicha labor. También a Roger Chartier por una lectura que permitió introducir variaciones a tiempo sobre una versión preliminar

\section{Bibliografía}

Agee, P. 1975 Into the company: CIA diary. Nueva York, Penguin Books.

Anderson, B. 1993 [1983] Comunidades imaginadas. Reflexiones sobre el origen y la difusión del nacionalismo. México, Fondo de Cultura Económica

Anderson, D. 1996 «Creating cultural prestige. Editorial Joaquín Mortiz». Latin American Research Review vol. 13, $n^{\circ} 2$, pp. 3-41. 
Castañeda, C. (Coord.) 2002 Del autor al lector. Historia del libro en México. México, CIESA.

Chartier, R. 1995 Espacio público, crítica y desacralización en el siglo XVIII. Barcelona, Gedisa.

Darnton, R. 2008 Los best sellers prohibidos en Francia antes de la revolución. Buenos Aires, Fondo de Cultura Económica.

Cosío Villegas, D. 1986 Memorias. México, Joaquín Mortiz - SEP.

Elias, N. 1989 El proceso de la civilización. Investigaciones sociogenéticas y psicogenéticas. México. Fondo de Cultura Económica.

Fondo de Cultura Económica 1984 Libro conmemorativo del 45 aniversario. México, FCE.

Goody, J. 1977 The domestication of sauvage mind, Cambridge, Cambridge University Press.

Habermas, J. 1984 Mudança Estrutural da esfera pública. Investigações quanto a uma categoria da sociedade burguesa. Río de Janeiro, Tempo Brasileiro.

López, A. 1993 «Conversaciones con Don Arnaldo Orfila Reynal». En Arnaldo Orfila Reynal. La pasión por los libros. Edición homenaje. Guadalajara, Universidad de Guadalajara, pp. 37 - 66.

Meyer, J. 2000 «México: revolución y reconstrucción en los años veinte». En L. Bethell (ed.) Historia de América Latina, vol. 9. Barcelona, Crítica, cap. 3, pp. 146-180.

Miceli, S. 2003 Nacional estrangeiro. História social e cultural do modernismo artístico em São Paulo. São Paulo, Companhia das Letras.

Myers, J. 2006 «Los senderos de la 'utopía de América': tres itinerarios y una encrucijada en la construcción de una formación cultural transregional», mimeo.

Monsiváis, C. 1993 «Arnaldo Orfila y la ampliación del lectorado». En Arnaldo Orfila Reynal. La pasión por los libros. Edición homenaje. Guadalajara, Universidad de Guadalajara, pp. 27 - 36.

Pollak, M. 2006 Memoria, olvido, silencio. La producción social de identidades frente a situaciones límite. La Plata, Ediciones Al Margen.

Saunders, F. S. 2001 La CIA y la Guerra fría cultural. Barcelona, Debate.

Sorá, G. 1999 «La Maison et l'Entreprise. José Olympio et l'évolution de l'édition au Brésil». Actes de la Recherche en Sciences Sociales $\mathrm{n}^{\circ} 126-127$, pp. $90-102$.
Sorá, G. 2003 Traducir el Brasil. Una antropología de la circulación internacional de ideas, Libros del zorzal, Buenos Aires.

Sorá, G. 2008a «Misión de la edición para una cultura en crisis. El Fondo de Cultura Económica y el americanismo en tierra firme». En Carlos Altamirano (dir.), Historia de los intelectuales en América Latina (vol II), Buenos Aires, Katz Editores (en prensa).

Sorá, G. 2008b Brasilianas. José Olympio e a gênese do campo editorial no Brasil. San Pablo, Edusp (en prensa).

Suárez de la Torre, L. (Coord.) 2001 Empresa y cultura en tinta y papel (1800-1860). México, Instituto Mora-UNAM.

Tarcus, H. 2007 Marx en la Argentina. Sus primeros lectores obreros, intelectuales y científicos. Buenos Aires, Siglo XXI.

Universidad de Guadalajara. 1993 Arnaldo Orfila Reynal. La pasión por los libros. Edición homenaje. Guadalajara.

Venuti, L. 1995 The translator inviibility. Londres - Nueva York, Routledge.

Wagner, A. 1979 «Bibliotecas marxistas e escolas de Partido». Río de Janeiro, PPGAS - Museu Nacional, mimeo.

Wright Mills, C. 1961 Escucha yanqui! La Revolución en Cuba. México, Fondo de Cultura Económica.

Zaid, G. (comp.) 1985 Daniel Cosío Villegas. Imprenta y vida pública. México, FCE.

1 En las crónicas de estos hechos se llega a mencionar hasta quinientos intelectuales manifestándose a favor del editor (p.e. Orfila Reynal en Universidad de Guadalajara 1993, pp. 11 y 15; Orfila Reynal, en entrevista realizada por Guillermo Schavelzon en La Habana el 4 de febrero de 1982, inédita).

${ }^{2}$ La mayor parte del material empírico de este trabajo fue compilada en trabajo de campo realizado en la ciudad de México durante el mes de febrero de 2007. Ese trabajo de campo fue financiado con fondos de un Proyecto PIP (6216) de CONICET. El archivo y la biblioteca del Fondo de Cultura Económica y el acervo histórico de Siglo XXI, fueron los sitios de origen de la mayor parte del corpus documental aquí analizado.

3 «Un sistema o modo de comunicación también conlleva el control de esta tecnología, el hecho de estar en manos de una jerarquía política o religiosa, de ser un sistema de escribas o 'del pueblo' (...) La introducción de la escritura tuvo gran influencia en la política, en la religión y en la economía» (Jack Goody 1977: 20).

${ }^{4}$ Cómo estudios ejemplares en América Latina sobre la significación de la edición en la afirmación de una ideología singular como el marxismo, véanse el pionero 
estudio de Wagner (1979) y el reciente libro de Tarcus (2007).

5 Relatividad connota que esa condición salta en el contraste, o en la mutua determinación entre el conjunto de categorías que pueblan el mundo de la cultura escrita e impresa: el escritor, el lector, el comentador, el librero; el autor, el intelectual, el crítico, etc. Sobre la invisibilidad del traductor, véase Venuti 1995. Sobre la relación traductor - editor, véase Sorá 2003.

6 Robert Darnton (2008) se destaca entre los historiadores del mundo del libro que han trabajado sobre esta clase de hechos. Esta perspectiva también se nutre de las particularidades de las situaciones límite pensadas por Michael Pollak (2006) al estudiar la memoria de víctimas de la Shoa.

7 De un modo más específico, o en función de los vínculos más directamente revelados por este estudio, también interesa responder: ¿Cuál fue el lugar de Argentina en la afirmación de los proyectos editoriales del Fondo de Cultura Económica en particular y de la cultura mexicana en general? ¿Cuál fue el lugar de México para el desarrollo de proyectos de intelectuales argentinos y para la imaginación de una cultura americana?

${ }^{8}$ Esta colección lanzó 17 títulos de autores como Esquilo, Eurípides, Platón, Dante, Goethe. En ediciones rústicas de tapas verdes, cada libro tuvo una tirada de 50.000 ejemplares y fue distribuido gratuitamente entre sectores excluidos de la cultura letrada, como los campesinos. Junto a esos títulos, también se distribuyeron libros de lectura, de historia y geografía (Acevedo Escobedo 1962: 417). El siguiente testimonio jocoso de Arnaldo Orfila Reynal lleva a pensar aquella iniciativa como un peculiar experimento romántico: «Tengo tan presente una vez que, seríamos 8 o 10 personas en su despacho, de pronto, por una puerta lateral entra Julio Torri y le dice a Vasconcelos: 'oye Pepe, acabo de regresar de Puebla y sabes qué'. ¿Qué?, contesta Vasconcelos. 'Hubo una magnifica cosecha de maíz en todo el estado'. Bien, ¿y qué con eso? 'Pues que me han informado que la cosecha se debe no tanto a las lluvias que hubo, sino a que todos los campesinos se leyeron el Plotino'. Todos reímos, pues era fama que a Plotino no lo entendía nadie» (memoria de Orfila Reynal de su visita a México en 1921, reproducida en López 1993: 41-42).

${ }^{9}$ Este proceso fue posible por la capacidad del General Álvaro Obregón para lograr consenso entre el ejército, los sindicatos y el movimiento agrarista de Zapata. Es indispensable considerar que por entonces México había pasado a ser el cuarto productor mundial de petróleo (Meyer 2000: 146 y ss.).

10 «Alguna vez, en 1923 o 1924, saliendo de una larga conversación con el Maestro [Vasconcelos], Cosío le dijo a su compañero Andrés Henestrosa: ¿Sabes quién va a ser el próximo presidente de México? Vasconcelos. Me dijo que Obregón habló con él para dejarlo como sucesor. Y ¿sabes quien va a seguir después? Cosío Villegas. Me dijo que, al terminar su presidencia, me la deja'» (Zaid, 1985: XII).

1 Según relató Cosío Villegas en sus memorias, Ortega y Gasset vetó el proyecto «alegando como única razón que el día en que los latinoamericanos tuvieran que ver algo en la actividad editorial de España, la cultura de España y la de todos los países de habla española 'se volvería una cena de negros' "(Cosío Villegas 1986: 146).

12 Esta alianza polar fue interpretada por el propio Cosío Villegas en el libro Extremos de América, editado en Tierra Firme en 1949.

${ }^{13}$ El Colegio Nacional inició sus actividades en 1910 y contaba con un internado para recibir alumnos de todo el país. En sus inicios se hablaba de esa institución como la base para una Oxford americana. Los profesores eran reclutados entre las figuras de mayor prestigio cultural y profesional de Buenos Aires y La Plata. En el Colegio, Orfila tuvo experiencias en la elaboración de periódicos. Durante ese período también participó como promotor de una universidad obrera.
${ }^{14}$ Para un abordaje de la trayectoria de Pedro Henríquez Ureña (hijo de uno de los principales políticos de República Dominicana en el cambio de siglos XIX al XX) y su vínculo con las vanguardias intelectuales mexicanas que en los años 10 se nuclearon en el Ateneo, véase Myers 2006.

15 Alejandro Korn fue médico y político. Su reconocimiento, sin embargo, es como filósofo, como el más incisivo crítico del positivismo y propulsor del neokantismo en la Argentina de aquellos años. Su libroLa libertad creadora, fue un slogan de Renovación y dio nombre a una revista homónima a inicios de los años 40 , cuando los miembros de Renovación ya se fundían en los proyectos de la Universidad Popular Alejandro Korn. Orfila Reynal nunca dejó de promover la figura de ese «maestro de la juventud», quien aparece retratado, por ejemplo, en muchos artículos de La Gaceta del FCE, en los años 50.

16 «Mi relación con los mexicanos se estrechaba cada vez más. Me enviaban constantemente libros y periódicos, me llamaban el 'Cónsul de México'. Yo les mandaba cosas, les informaba de lo que pasaba en Argentina y a la vez estaba informado de todo lo que pasaba en México.» (Orfila Reynal, en López 1993: 47). En el número 3 de Valoraciones apareció un texto firmado por Daniel Cosío Villegas. México también marcó presencia en la revista con textos de otros escritores como Alfonso Reyes, reproducciones de pinturas de Diego Rivera y viñetas mesoamericanas.

17 Entre ellas, se destacó la traducción de los más conspicuos representantes de la sociología alemana: por ejemplo, Economía y Sociedad de Max Weber (1944), Ideología y Utopía de Karl Mannheim (1941), Historia de la cultura de Alfred Weber (1941). También vieron la luz decenas de libros de autores contemporáneos «fundamentales», como John M. Keynes, Paul Sweezy, Ernst Cassirer, Erich Fromm, Maurice Dobb, Martin Heidegger, Levin Schûcking, Ralph Linton, etc. Predominaron, sin embargo, traducciones de autores fundadores de todas las disciplinas sociales y humanas: los principales representantes de la economía clásica (también El Capital de K. Marx en tres tomos, en 1946), antropólogos como J. Frazer, filósofos como W. Dilthey, etc.

${ }^{18}$ El ensayista Carlos Monsiváis (1993: 28) afirmó que Letras Mexicanas fue le medio más significativo para «la fijación del canon» de la literatura mexicana moderna.

${ }^{19}$ En 1955, el escritor Juan José Arreola sintetiza esa consagración del siguiente modo: «México se ha dado cuenta de que el Fondo, como la pintura y las películas, lleva su nombre a todas partes del mundo en la etiqueta prestigiosa de los libros que se dividen ya en series numerosas» (citado en Arciniega 1994: 127).

20 Martí Soler trabajó junto a Orfila Reynal desde los 25 años, cuando en 1959 ingresó al sector de producción del FCE. Luego fue el gerente de esa área estratégica en Siglo XXI. Se casó con Elsa Cecilia Frost, subgerente de producción del FCE y amiga personal de Laurette Séjourné, la mujer de Orfila.

${ }^{21}$ Entrevista a Martí Soler realizada en México D.F., en febrero de 2007.

22 Joaquín Diez Canedo fue gerente de producción del FCE hasta 1962, cuando fundó su propia editorial: Joaquín Mortiz. Ali Chumacero, quien hasta entonces se desempeñaba como una de las principales figuras de ese departamento, ocupó su cargo. Fue a través de Joaquín Mortiz que Diez Canedo granjeó reconocimiento como fino catador de literatura. Si Letras Mexicanas iluminó la vanguardia literaria de México de la década de 1950, Joaquín Mortiz hizo lo propio con la vanguardia de la década siguiente (Anderson 1996).

${ }^{23}$ Lo mismo podría ser dicho sobre la figura del intelectual, desde un punto de vista antropológico que considere no solamente las características típico-ideales de esa figura en Occidente desde el affaire Dreyfus (el combate moral por la razón y la justicia, a través de la escritura, primordialmente), sino la de aquellos individuos que en toda sociedad (escasa o ampliamente diferenciada) generan acciones «creativas» sobre la cultura (Goody 1977). Desde esta perspectiva Orfila fue un intelectual y 
así puede interpretase el reconocimiento que como tal le fue atribuido en numerosas ocasiones. Este comentario, finalmente, permite revelar el alcance de la acción de Orfila como selector de textos y autores. De modo convergente a Cosío Villegas, privilegió la elección de un amplio número de autores y textos filiados a posiciones estéticas e ideológicas próximas a un reformismo humanista capaz de resaltar las singularidades y potencial universal de un pensamiento propio, americano. Da cuenta de esto, por ejemplo, la edición por el FCE de amigos argentinos de Orfila como José Luís Romero, Ezequiel Martínez Estrada, Carlos Sánchez Viamonte, Enrique Anderson Imbert, Sergio Bagú y Leopoldo Portnoy, entre otros.

${ }_{24}$ Sería necesario un estudio histórico-cuantitativo del catálogo para verificar un giro desde el predominio cultural norteamericano (tal vez en la cima porcentual hasta mediados de los años 50) hacia otro europeo occidental, especialmente francés.

25 «Él contaba por ejemplo, que el Che llegó a México a oscuras. Él lo recibió como argentino que era. Llegó a casa de Orfila, recién llegado a México. Y él le regaló $E l$ Capital.» (Martí Soler, entrevista, febrero de 2007). En la versión de Tatiana Coll, Guevara conoció a Orfila en 1955 cuando, posiblemente luego del golpe al gobierno de Perón, el editor habló junto a otros intelectuales sobre la situación argentina.

${ }^{26}$ Entrevistada en México D.F. en febrero de 2007. Tatiana Coll, socióloga, es hija de una amiga íntima de Laurette Séjourné. Su padre murió joven y desde entonces ella pasó a ser, según su expresión, como una «hija adoptiva» del binomio Séjourné - Orfila Reynal, quienes no tuvieron hijos biológicos.

27 La simpatía de Arnaldo y Laurette por ciertos movimientos guerrilleros no podía aflorar dada la visibilidad pública de ambos. En su entorno y en la editorial, sin embargo, abrigaron condiciones para la generación de solidaridad entre personas directamente ligadas a la lucha armada.

${ }^{28}$ En 1969, en un acto realizado en La Habana, Fidel Castro y la familia de Guevara depositaron en las manos de Orfila Reynal los diarios del Ché para su edición por Siglo XXI y su difusión internacional.

29 Para un análisis de los significados del término «casa» editorial y las condiciones de aparición de figuras patriarcales en el actividad editorial, véase Sorá 1999.

${ }^{30}$ La Gaceta era el órgano de prensa del Fondo de Cultura Económica. Comenzó a salir en 1953. Era un tabloide que llegaba a las 12 páginas con reseñas de libros publicados por la editorial, notas sobre vida intelectual, académica, literaria y política. No existía un periódico similar en América Latina. El renombre de la editorial y las alternativas de anticipación intelectual que proponía, hicieron que circulara por todo el continente.

31 Esta incluía la traducción de libros de autores norteamericanos al árabe, persa, urdú, bengalí, malayo e indonesio; la impresión de más de 17 millones de libros de texto, especialmente en Afganistán, Irán y la República Árabe Unida, etc.

32 Arnaldo Orfila Reynal, «Las verdaderas proporciones de una 'Operación Libro'». La Gaceta del Fondo de Cultura Económica ${ }^{\circ}$ 89: 2, enero de 1962.

33 «Los programas de actividad para el extranjero y el orgullo nacional» y «La Franklin Publications contesta al Fondo de Cultura Económica». La Gaceta del Fondo de Cultura Económica n 93: 4, mayo de 1962.

${ }^{34}$ Arnaldo Orfila Reynal, «Un diálogo fructífero entre los editores mexicanos y sus colegas de los Estados Unidos». La Gaceta del Fondo de Cultura Económica $\mathrm{n}^{\circ}$ 93: 4, mayo de 1962.

35 Charles Wright Mills era un profesor de la Universidad de Columbia cuya obra era valorada como un contrapunto al positivismo de la sociología de Chicago. Fue autor de un libro pionero sobre La elite del poder en Estados Unidos. El FCE publicó su traducción en 1957, al año de su edición por la Oxford University Press. Listen yanqui fue escrito en 1960 y publicado por McGraw-Hill.
No era un libro académico sino testimonial, escrito como cartas de viajero. Su concepción fue efecto de visitas a Río de Janeiro y México realizadas al poco tiempo de estallar la revolución en Cuba. Ante la incapacidad de acompañar los intensos debates que escuchaba Mills en América Latina sobre los hechos de Cuba, decidió emprender un viaje a la isla. El renombre de Mills al llegar a Cuba y la valoración de un libro como La elite del poder le permitió entrevistar a toda la plana mayor del gobierno revolucionario, soldados, intelectuales, periodistas y profesores. El objetivo del libro fue «presentar la voz del revolucionario cubano con la mayor claridad y fuerza posible». Este objetivo buscó contra-restar el sesgo y desinformación de las noticias sobre Cuba en la opinión pública norteamericana y motivar la toma de conciencia de sus connacionales sobre las transformaciones del mundo por venir. Para ello, Mills se propuso dar voz a los líderes de la revolución: «Porque la voz de Cuba es hoy la voz del bloque de naciones hambrientas, y el revolucionario cubano habla ahora -con gran efectividad- en nombre de ese bloque. Lo que los cubanos dicen y hacen hoy lo dirán y harán mañana otros pueblos hambrientos de América Latina» (Wright Mills 1963: 9).

36 La fascinación del sociólogo norteamericano por Cuba se afirmaba en cada línea del artículo: «Lo que más me impresiona de las posibilidades culturales en Cuba es el deseo de aprender y la amplitud de criterio de muchos de los jóvenes que integran el gobierno revolucionario de Cuba. En 20 años de enseñanza, de labor permanente como escritor y de viajes frecuentes, nunca había encontrado una pasión tan sostenida por el conocimiento ni una conciencia tan inteligente de lo que hace falta estudiar».

37 Este libro fue presentado con un prólogo de Gino Germani, donde el sociólogo italo-argentino aborda la significación de la traducción como instrumento de la fase de universalización en la que se encontraba la sociología mundial en construcción. Al igual que La elite del poder (1959), La imaginación sociológica (1961) y Poder, política y pueblo (1964) salieron por la Sección de Sociología, dirigida por J. Medina Echevarría.

38 «Mario Monteforte Toledo: vida y muerte de Wright Mills», La Gaceta. Publicación del Fondo de Cultura Económica (IX) 92: 3, abril de 1962. Para denotar la presencia de Mills entre el «nosotros», el texto centraba una fotografía del sociólogo en el FCE con la siguiente leyenda: «Wright Mills en las oficinas de nuestra casa. Lo acompañan miembros de la Junta de Gobierno e intelectuales de prestigio» (cursivas mías).

39 Arciniega (1994: 141) sustenta la idea que la sustitución de Orfila Reynal por Azuela fue el resultado de críticas previas hacia el FCE, realizadas por personas como Luis Garrido (abogado, filósofo y rector de la UNAM entre 1948 y 1953) o José Chávez Morado (artista plástico reconocido como valuarte del arte figurativo de la Escuela mexicana de Pintura) relativas a la escasa edición de temas mexicanos por parte de la editorial dirigida por Orfila.

40 Tras el escándalo generado a lo largo de 1965 por la edición del FCE de Los Hijos de Sánchez y luego de la dimisión de Orfila Reynal, este título pasó a ser editado por la editorial Joaquín Mortiz. El compromiso ideológico asumido por los editores de este sello fue manifiesto al anexar al libro los documentos generados por la Procuraduría de la República sobre el caso Lewis - Orfila. Esta rica documentación permite reconstruir los avatares del proceso judicial: la secuencia de acontecimientos que desembocaron en el juicio, los argumentos de la querella y la defensa, ideas y condicionamientos desencadenados alrededor del affaire. En el presente texto, decidí recortar el análisis de esos hechos por cuestión de espacio.

${ }^{41}$ Así recordaba Arnaldo tal situación, hacia 1987: «’ Pues hemos pensado que se debería retirar'. -¿Por qué?, contesto. -Bueno, porque es extranjero, es usted argentino'. -Pero eso ya lo sabían cuando vine desde 1948 de Buenos Aires; pero oiga, yo soy de alma mexicana (...) soy tan mexicano como usted» (en López 1993, p. 61)

${ }^{42}$ Mariano Azuela fue un médico que como tal participó en las luchas revolucionarias entre las huestes 
de Emiliano Zapata. Su obra de teatro Los de abajo, se basa en sus vivencias durante aquellos hechos. Fue publicada en entregas parciales al periódico El Paso de Texas (EEUU), en 1916. Su consagración nacional e internacional llegó recién con la tercera edición en libro, hacia 1925. El FCE lo reeditó en la Colección Popular en 1958, con motivo de los preparativos del 50 aniversario de la Revolución. Con el correr de los años, devino el título de mayores ventas de la editorial: hasta 1984, se habían impreso 590.000 copias, en 12 reimpresiones (FCE 1984: 124).

43 Ésta información fue revelada a partir de documentos desclasificados de la CIA en 2006 a pedido de la ONG Archivos para la Seguridad Nacional y por los resultados de la Fiscalía Especial para los Movimientos Sociales y Políticos del Pasado (Femospp) creada durante el gobierno de Vicente Fox (2000 - 2006). José Carreño, «Echeverría y Díaz Ordaz engañaron a la CIA«, El Universal, 19/10/2006. Philip Agee (1975) también aborda el vínculo de Ordaz y Echeverría con la CIA.

44 Estas afirmaciones fueron reproducidas por numerosos medios. "Orfila Reynal ataca a nuestro gobierno», publicaba El Redondel el 22 de octubre de 1967. Ese mismo día el diario Novedades concluía que lo más absurdo era que «los apátridas de la maffia» le habían rendido a Orfila, «un homenaje de 'desagravio'». Otras notas aparecieron en el diario Excelsior (Manuel Mejido, $14 / 10 / 1967)$ y en las revistas Sucesos $(11 / 11 / 1967)$ y Gente (Antonio Estrada, 16/11/1967)

${ }^{45}$ Según el periodista Jacobo Zabludovsky, quien en la década de 1960 fue encargado del telenoticiero del Telesistema Mexicano (hoy Televisa), por aquellos años el gobierno de Díaz Ordaz estableció un férreo control sobre las informaciones que se transmitían sobre el país. Él mismo llegó a recibir una llamada telefónica del presidente para pedir explicaciones sobre el tenor de las informaciones transmitidas sobre la masacre de estudiantes («Nunca creí que hubiera conjura comunista en 68: Zabludovsky». La Jornada, 28 / 9 / 1998).

${ }^{46}$ A diferencia de los dos apartados anteriores, la caracterización de «los hijos» de Orfila precisaría de mayor problematización. Esta induciría al análisis de los fundamentos del habitus patriarcal que Orfila Reynal desplegó sobre su mundo editorial. Debería considerarse, en primer, lugar, la estructura de su propia «familia»: el editor no fue padre. Luego las representaciones sobre sus editoriales como «casas». También la naturaleza de sus relaciones personales con empleados y escritores: fraternidad, apadrinamientos, etc. He reflexionado sobre estas cuestiones en Brasil, para el caso del editor José Olympio (Sorá 2008b).

${ }^{47}$ Así se lo comunicaba Orfila a Fuentes: «Desde ahora le otorgo el cargo honorífico de representante de Siglo XXI ante autores y escritores europeos que pueda usted encontrar. Como comprenderá, pienso presentar un plan editorial abarcando varias disciplinas y en literatura, por ahora, nos ceñiremos a lo latinoamericano de primera calidad. Dejaremos la literatura extranjera para los otros colegas; pero si encuentra usted títulos de libros que considere útil hacer traducir y difundir en nuestra lengua, mándeme las fichas bibliográficas o pídame las primeras opciones, desde ahora, a los editores que pueda visitar» (carta de Orfila Reynal a C. Fuentes, 9/12/65). Ya en febrero Fuentes intercede para que Siglo XXI publique Report on China de Lewis Karol. En cartas a otros escritores, Fuentes se representaba como «consejero princeps de Orfila». En la respuesta a Orfila, Fuentes le comunicaba: «Más tarde, quisiera publicar con Siglo XXI un libro de ensayos. Ayúdeme a pensar en esto. Tengo tanta fe y entusiasmo en esa empresa, en lo que significa para México y para América Latina. Podríamos quizás, pensar en dos volúmenes: uno de critica literaria, viajes, crónicas; otro de artículos y ensayos políticos.»

${ }^{48}$ Aproximadamente $40 \%$ de la producción del FCE se comercializaba en el estranjero. Esta cifra, ciertamente, observa oscilaciones según diferentes períodos.

${ }^{49}$ En Nacional estrangeiro, Sergio Miceli (2003) propone un estudio ejemplar para pensar las condiciones sociales que llevan a la acción complementaria entre extranjeros en otras culturas nacionales y de nativos que apuestan a la internacionalización, en la construcción de espacios de producción simbólica en particular y de esferas públicas en general. La manifestación de ese modelo estructural en el caso aquí estudiado señala el interés por observar esa dinámica en otros contextos nacionales y por avanzar en un proyecto comparativo.

50 He registrado esa asociación en periódicos de la época y en numerosos testimonios y trabajos académicos del presente. La misma es más frecuente en opiniones realizadas por periodistas, investigadores, escritores no mexicanos, especialmente argentinos. 